\title{
Aging-relevant human basal forebrain cholinergic neurons as a cell model for Alzheimer's disease
}

\author{
Shuaipeng $\mathrm{Ma}^{1,2 \dagger}$, Tong Zang ${ }^{1,2+}{ }^{+}$Meng-Lu Liu ${ }^{1,2}$ and Chun-Li Zhang ${ }^{1,2^{*}}$ (D)
}

\begin{abstract}
Background: Alzheimer's disease (AD) is an adult-onset mental disorder with aging as a major risk factor. Early and progressive degeneration of basal forebrain cholinergic neurons (BFCNs) contributes substantially to cognitive impairments of AD. An aging-relevant cell model of BFCNs will critically help understand AD and identify potential therapeutics. Recent studies demonstrate that induced neurons directly reprogrammed from adult human skin fibroblasts retain aging-associated features. However, human induced BFCNs (hiBFCNs) have yet to be achieved.
\end{abstract}

Methods: We examined a reprogramming procedure for the generation of aging-relevant hiBFCNs through virusmediated expression of fate-determining transcription factors. Skin fibroblasts were obtained from healthy young persons, healthy adults and sporadic AD patients. Properties of the induced neurons were examined by immunocytochemistry, QRT-PCR, western blotting, and electrophysiology.

Results: We established a protocol for efficient generation of hiBFCNs from adult human skin fibroblasts. They show electrophysiological properties of mature neurons and express BFCN-specific markers, such as CHAT, P75NTR, ISL1, and VACHT. As a proof-of-concept, our preliminary results further reveal that hiBFCNs from sporadic AD patients exhibit time-dependent TAU hyperphosphorylation in the soma and dysfunctional nucleocytoplasmic transport activities.

Conclusions: Aging-relevant BFCNs can be directly reprogrammed from human skin fibroblasts of healthy adults and sporadic AD patients. They show promises as an aging-relevant cell model for understanding AD pathology and may be employed for therapeutics identification for AD.

Keywords: Alzheimer's disease, Aging, BFCNs, Reprogramming, Fibroblasts, Nucleocytoplasmic transport, TAU hyperphosphorylation

\footnotetext{
* Correspondence: chun-li.zhang@utsouthwestern.edu

${ }^{\dagger}$ Shuaipeng Ma and Tong Zang contributed equally to this work.

'Department of Molecular Biology, University of Texas Southwestern Medical Center, 6000 Harry Hines Boulevard, Dallas, TX 75390, USA

${ }^{2}$ Hamon Center for Regenerative Science and Medicine, University of Texas Southwestern Medical Center, 6000 Harry Hines Boulevard, Dallas, TX 75390 USA
}

(c) The Author(s). 2020 Open Access This article is licensed under a Creative Commons Attribution 4.0 International License, which permits use, sharing, adaptation, distribution and reproduction in any medium or format, as long as you give appropriate credit to the original author(s) and the source, provide a link to the Creative Commons licence, and indicate if changes were made. The images or other third party material in this article are included in the article's Creative Commons licence, unless indicated otherwise in a credit line to the material. If material is not included in the article's Creative Commons licence and your intended use is not permitted by statutory regulation or exceeds the permitted use, you will need to obtain permission directly from the copyright holder. To view a copy of this licence, visit http://creativecommons.org/licenses/by/4.0/ The Creative Commons Public Domain Dedication waiver (http://creativecommons.org/publicdomain/zero/1.0/) applies to the data made available in this article, unless otherwise stated in a credit line to the data. 


\section{Background}

The basal forebrain cholinergic system, located to the front of and below the striatum, is the predominant source of cortical cholinergic input [1]. Early and progressive degeneration of basal forebrain cholinergic neurons (BFCNs) contributes substantially to cognitive impairments of human patients with Alzheimer's disease (AD) $[2,3]$. The importance of BFCNs in $\mathrm{AD}$ is further demonstrated in animal models, the behavior of which can be significantly improved through cell grafts $[4,5]$ or treatments promoting BFCN function [6]. As such, cell models of human BFCNs will be invaluable in understanding $\mathrm{AD}$ and identifying novel therapeutics.

BFCNs can be derived from embryonic stem cells (ESCs) or induced pluripotent stem cells (iPSCs) through sequential treatments with signaling molecules [4, 5, 713]. However, neurons derived from ESCs or iPSCs are young and do not exhibit aging-associated features $[9,14-$ 17]. These young neurons are advantageous in understanding neural development and for transplantationbased therapies $[4,5,7,11,12]$. However, they may not be appropriate as a cell model for late-onset neurodegeneration, such as AD, a majority of which are sporadic without any known genetic mutations. We and others have recently shown that neurons can be directly reprogrammed from skin fibroblasts of adult human patients [15-20]. These induced neurons do not pass through an ageresetting progenitor stage and therefore retain agingassociated features, such as DNA damages, chromatin structures and nuclear organization, and increased biomarker of cellular senescence [15-17]. To date, however, human induced BFCNs (hiBFCNs) from adult skin fibroblasts have not been reported.

Here, we report a protocol for direct reprogramming of adult human skin fibroblasts into electrophysiologically mature hiBFCNs. The reprogramming efficiency is similar between fibroblasts of healthy and sporadic AD patients. The reprogrammed neurons retain agingassociated features. Our preliminary results further indicate that hiBFCNs from sporadic AD patients exhibit time-dependent TAU hyperphosphorylation and impairment in nucleocytoplasmic transport. hiBFCNs may be useful for understanding the molecular mechanisms and discovering novel therapeutics for age-dependent progressive AD.

\section{Results}

\section{Rapid and efficient generation of hiBFCNs from adult human skin fibroblasts}

We previously showed that human skin fibroblasts can be directly converted into cholinergic neurons without passing through a progenitor stage [18]. However, they lack the expression of LHX8 (also known as LHX7 or L3 [21]) and GBX1, transcription factors crucial for BFCN specification [7, 12, 22-26]. We then examined these two transcription factors in various combinations with our original reprogramming factors (NEUROG2 and SOX11) for cholinergic neurons [18]. Two days postviral infection (dpi), transduced cells were switched to neuron-induction medium $[18,19]$. Neuronal conversion was monitored daily by live-cell fluorescence microscopy. Cells were replated at $14 \mathrm{dpi}$ to remove most nonreprogrammed fibroblasts and were seeded into astrocytes-coated plates with maturation medium for long-term survival (Fig. 1a).

Although induced neurons (iNs) could be obtained from normal (NL) healthy patient fibroblasts, some of them expressed HB9, a transcription factor specifically expressed in spinal motor neurons. This was likely due to a dominant role of NEUROG2 in motor neuron specification $[18,27,28]$, whereas SOX11 promotes neuronal survival but not fate reprogramming [18]. We next replaced NEUROG2 with ASCL1, since both of them work as pioneer transcription factors dominantly controlling gene expression and neuronal fates $[29,30]$. Furthermore, $\mathrm{ASCL}^{+}$progenitors can give rise to cholinergic neurons [23, 31-33].

Remarkably, a combination of the lentivirus ASCL1IRES-GFP-T2A-Sox 11 and LHX8-IRES-GBX1 (hereafter referred to as $A S L G$ ) enabled a majority ( $>90 \%$ ) of the virustransduced adult NL fibroblasts (indicated by the coexpressed GFP) to become $\mathrm{TUJ}^{+}$and $\mathrm{CHAT}^{+}$neuronlike cells at $28 \mathrm{dpi}$ (Fig. 1b-d). During this conversion process, cells rapidly changed their initially flat, spread-out morphology to one with bipolar and multipolar processes. They exhibited round or pyramidal somas, condensed nuclei, long axons, and multiple neurites (Fig. 1b, Additional file 1: Figure S1A). Based on our prior experience with human induced motor neurons (hiMNs) [16, 18, 19], we also examined a polycistronic lentiviral vector, $L H X 8$ $T 2 A-G B X 1$, so that both LHX8 and GBX1 would be expressed roughly at an equal molar ratio. However, this vector caused mass cell loss when examined at 4 dpi (Additional file 1: Figure S1B) and produced very few neurons at 28 dpi (Additional file 1: Figure S1C, D).

Immunocytochemistry showed ASLG-induced neurons expressed markers for mature neurons such as neurofilament 200 (NF200), MAP2, and synapsin 1 (SYN1) when examined at 28 dpi (Fig. 1e, Additional file 2: Figure S2A). They also expressed neuronal cell adhesion molecule L1CAM (Additional file 2: Figure S2B). Importantly, more than $90 \%$ of $\mathrm{GFP}^{+}$cells were stained positive for choline acetyltransferase (CHAT) (Fig. 1b-d) and vesicular acetylcholine transporter (VACHT) (Additional file 2: Figure $\mathrm{S} 2 \mathrm{C}$ ), two stereotypical markers for cholinergic neurons.

BFCNs are defined by their expression of neurotrophin receptor p75NTR and Trk receptors in addition to cholinergic markers [34-37]. In the basal forebrain 


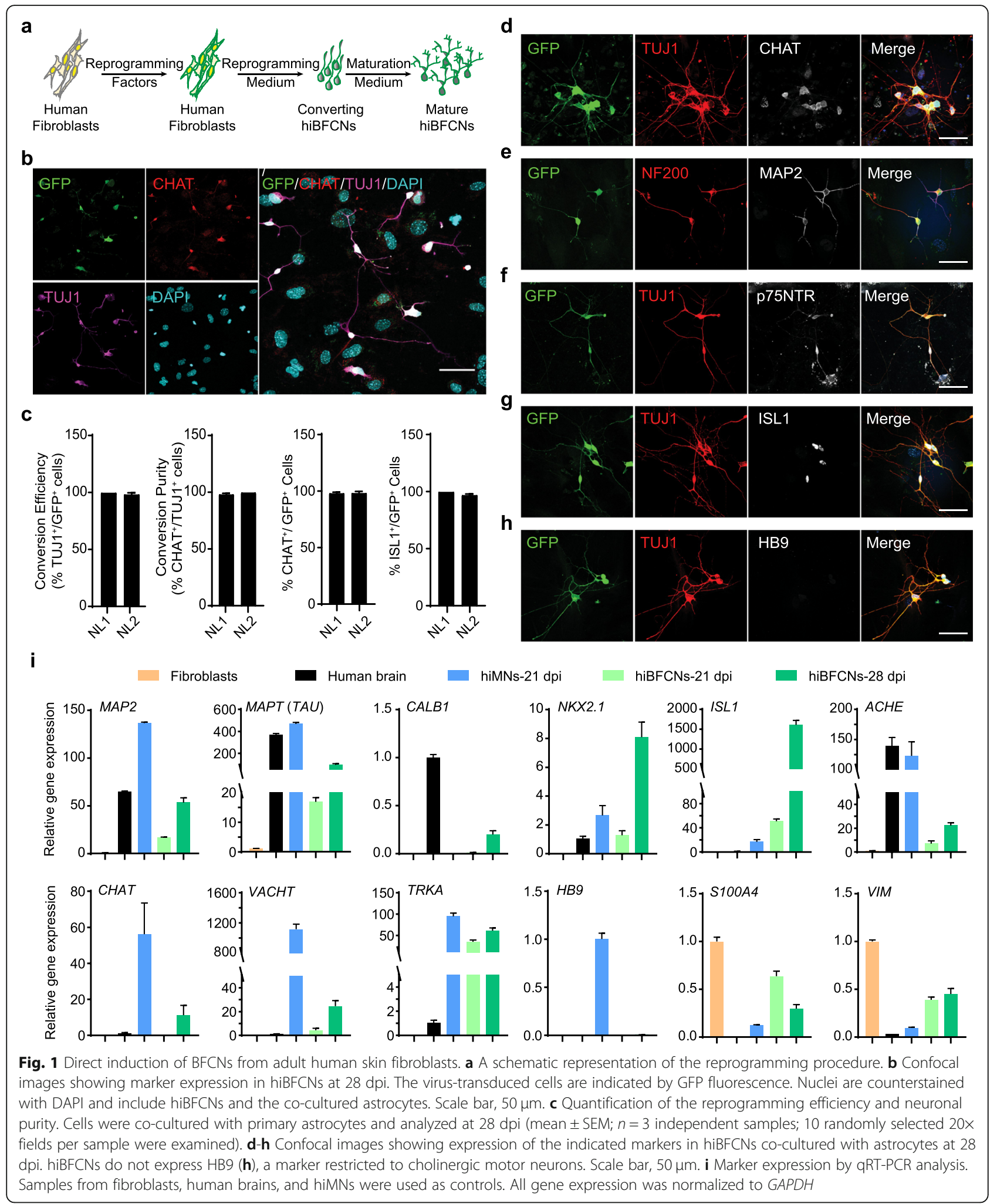

p75NTR is colocalized exclusively with cholinergic neurons [38, 39]. Immunocytochemistry showed that the reprogrammed neurons expressed markers for BFCNs, including p75NTR and the transcription factor ISL1 (Fig. 1f, g, Additional file 2: Figure S2D). ISL1 is the earliest marker of cholinergic fate neurons and it forms complexes with LHX8 or LHX3 to enhance gene expression for cholinergic specification 
[40-42]. More than 95\% $\mathrm{GFP}^{+}$cells expressed ISL1 (Fig. 1c, g). On the other hand, these ASLG-induced neurons did not express HB9 (Fig.1h), an exclusive marker for cholinergic motor neurons as shown in hiMNs [18, 19] (Additional file 2: Figure S2E). Based on these above characteristics, we named the ASLGinduced neurons as human induced BFCNs (hiBFCNs). Fibroblasts from adult AD patients could be similarly reprogrammed by $A S L G$ into hiBFCNs (Additional file 3: Figure S3).

The molecular properties of hiBFCNs were also examined by qRT-PCR (Fig. 1i). As controls, we included samples from human brains and fibroblast-converted hiMNs. hiBFCNs showed robust expression of genes enriched in neurons (MAP2, MAPT, CALB1) and BFCNs (ISL1, NKX2.1, CHAT, VACHT, ACHE, TRKA), whereas the motor neuron-specific marker $H B 9$ was not expressed. Due to contamination of non-converted fibroblasts in the samples, expression of fibroblast-enriched genes (S100A4, $V I M)$ was detected but much reduced in hiBFCN samples.

\section{The electrophysiological properties of hiBFCNs}

We used whole-cell patch-clamp recordings to examine the electrophysiological properties of hiBFCNs. A total of 44 out of 54 recorded hiBFCNs fired repetitive action potentials (APs) in response to depolarizing current injections in current clamp mode when examined at $49 \mathrm{dpi}$ and beyond (Fig. 2a). Neuronal capacitance, input resistance, and resting membrane potentials were measured at $8.41 \pm 0.40 \mathrm{pF}, 372.0 \pm$ $72.57 \mathrm{M} \Omega$, and $-31.37 \pm 2.60 \mathrm{mV}$, respectively (Fig. 2b-d). The AP threshold and delay of the first spike were $-30.14 \pm 0.845 \mathrm{mV}$ and $260.6 \pm 44.68 \mathrm{~ms}$, respectively (Fig. 2e, f). The AP half-width, amplitude, and frequency were approximately $8.48 \pm 1.54 \mathrm{~ms}, 87.46 \pm$ $3.27 \mathrm{mV}$, and $3.68 \pm 0.75 \mathrm{~Hz}$, respectively (Fig. $2 \mathrm{~g}-\mathrm{i}$ ). On the other hand, the maximum velocity of rise and decay, and the after-hyperpolarization were $57.37 \pm$ $7.48 \mathrm{~V} / \mathrm{s}, \quad-25.87 \pm 2.35 \mathrm{~V} / \mathrm{s}$ and $-14.33 \pm 1.21 \mathrm{mV}$, respectively (Fig. 2j-1).

In voltage-clamp mode, hiBFCNs showed typical inward sodium currents and outward potassium currents (Fig. $2 \mathrm{~m}$ ). The amplitudes of sodium currents $\left(I_{N a}\right)$, Atype potassium currents $\left(I_{A}\right)$, and delayed-rectifier potassium currents $\left(I_{d}\right)$ were respectively $-1221 \pm 173.5 \mathrm{pA}$, $311.7 \pm 35.36 \mathrm{pA}$, and $852.6 \pm 135.9$ pA (Fig. 2n-p). When injected with hyperpolarizing currents, voltage sags were observed in hiBFCNs (Fig. 2q, r). The hyperpolarization-activated currents $\left(I_{h}\right)$, elicited by hyperpolarizing voltage steps under voltage clamps, were about $-19.32 \pm 4.54 \mathrm{pA}$ (Fig. 2s, t). Together, these results show that hiBFCNs can become functionally mature exhibiting electrophysiological properties that are typical for mature neurons.

\section{hiBFCNs retain aging-associated features}

To examine whether directly reprogrammed hiBFCNs maintain aging-associated features, we derived hiBFCNs from fibroblasts of young (Young) and old (Old) human patients. The latter samples consisted of fibroblasts from both aged NL and sporadic AD patients. The reprogramming efficiency, which was about 92-94\%, was similar between all these patient cells (Fig. 3a). Interestingly, hiBFCNs from old patients had markedly fewer primary neurites, despite no significant difference between $\mathrm{NL}-$ and $\mathrm{AD}$ hiBFCNs when examined at 51 dpi (Fig. 3b, c).

We performed single-cell analysis after immunocytochemistry by using a set of molecular markers that were shown to reflect age-dependent cellular characteristics. These included $\gamma \mathrm{H} 2 \mathrm{AX}$, trimethylated $\mathrm{H} 3 \mathrm{~K} 9$ (H3K9me3), and heterochromatin protein $1 \gamma(\mathrm{HP} 1 \gamma)$ $[14,16,43]$. hiBFCNs were co-cultured with astrocytes and analyzed at $51 \mathrm{dpi}$. Consistent with our previous results [16], hiBFCNs from older donors showed a much larger number of $\gamma \mathrm{H} 2 \mathrm{AX}$ foci than those from younger donors $(p<0.0001$; Fig. 3d, e), whereas the expression level of $\mathrm{H} 3 \mathrm{~K} 9 \mathrm{me} 3$ and $\mathrm{HP} 1 \gamma$ was significantly reduced in old than young hiBFCNs $(p<0.0001$ for $\mathrm{HP} 1 \gamma$ and $p=$ 0.0446 for H3K9me3; Fig. 3d, e). Very interestingly, HP1 1 level was also markedly lower in AD than NL hiBFCNs ( $p=0.0162$; Fig. $3 f)$, indicating that it could be a molecular marker for the diseased neurons. In contrast, hiBFCNs exhibited no disease-associated differences in terms of $\gamma \mathrm{H} 2 \mathrm{AX}$ foci per cell and the expression level of nuclear H3K9me3 (Fig. 3f). Together, these results indicate that hiBFCNs from older donors indeed retain certain aging-associated features, consistent with prior reports on other directly reprogrammed neurons from human fibroblasts [14-17].

\section{Relatively normal survival and soma size of AD-hiBFCNs}

The survival of hiBFCNs was determined in co-culture with wild-type mouse astrocytes, which were required in general for neuronal growth and long-term culture. After replating at $14 \mathrm{dpi}$, survived hiBFCNs were quantified at 21 and 28 dpi. Cell counts were then normalized to the starting neuronal number for each sample at 14 dpi. The survival rates were heterogeneous among all the human samples, ranging from about 24 to $76 \%$ at 21 dpi and 20 to $62 \%$ at $28 \mathrm{dpi}$ (Fig. 4a, b). Statistical analysis failed to show a significant difference between NLand AD-hiBFCNs at both time points. Similarly, both NL- and AD-hiBFCNs showed heterogeneous but not significantly different soma sizes when analyzed at 51 dpi $\left(242-373 \mu \mathrm{m}^{2}\right.$; Fig. 4c). These results indicate that AD-hiBFCNs do not exhibit intrinsic deficits on cell survival or soma sizes. 


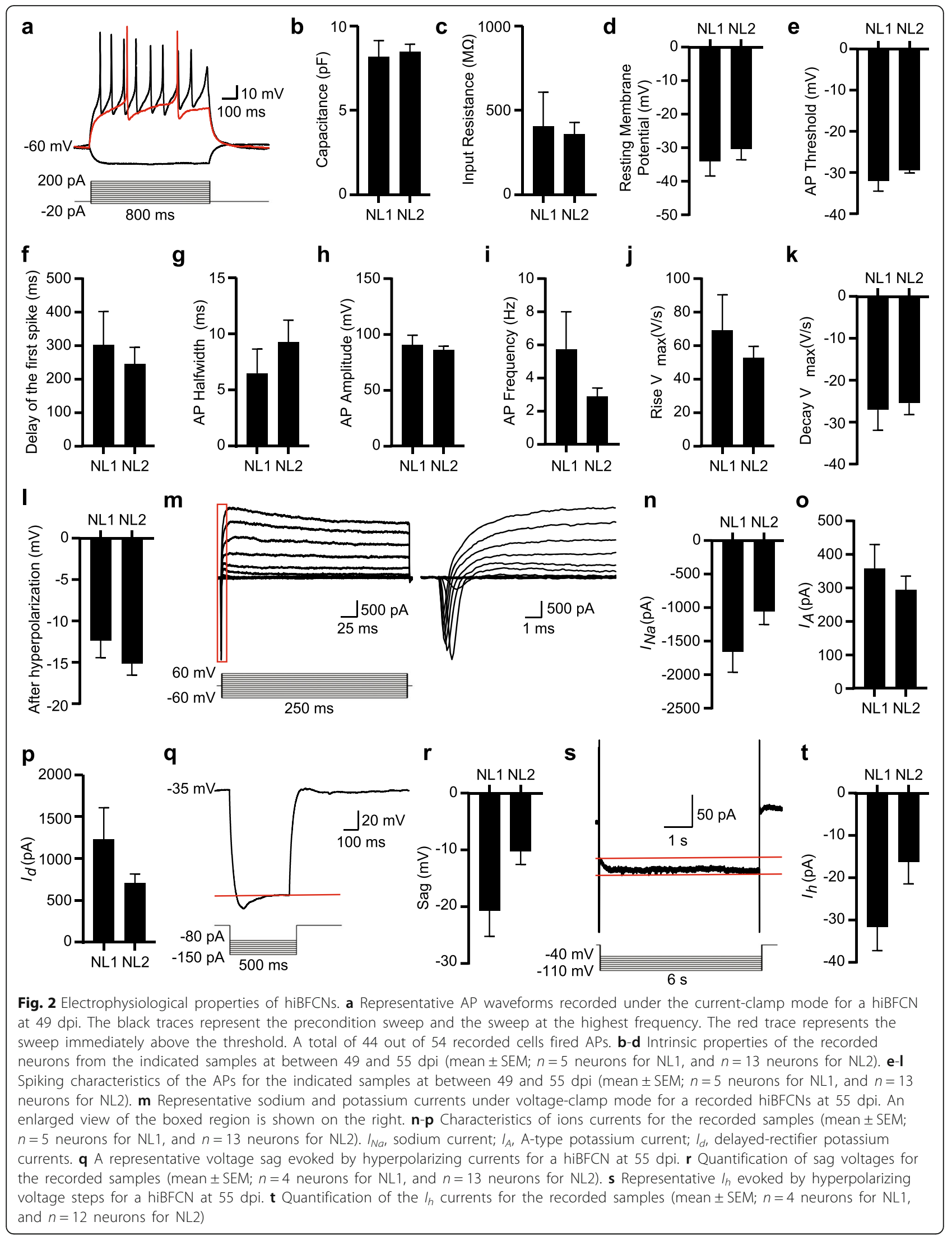




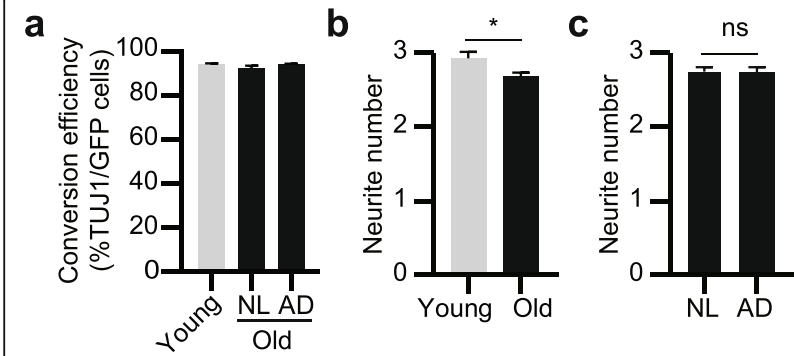

d
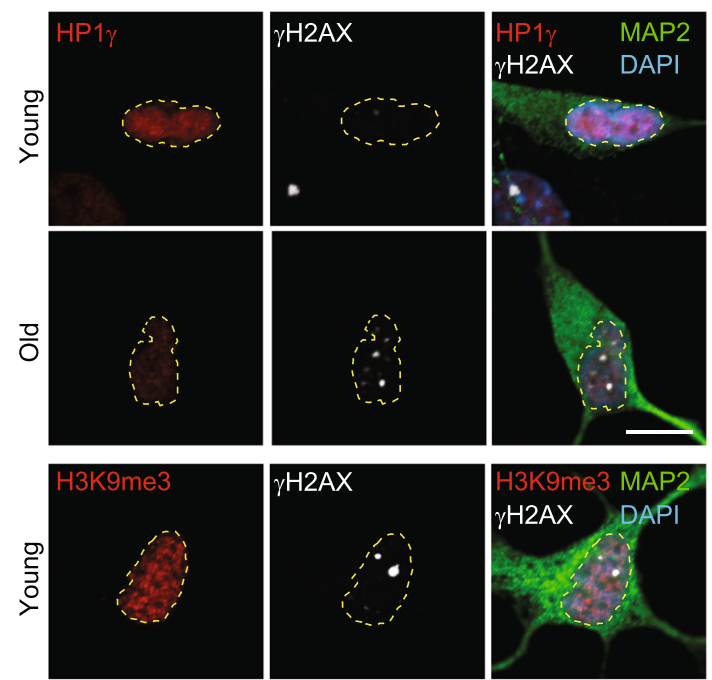

흥
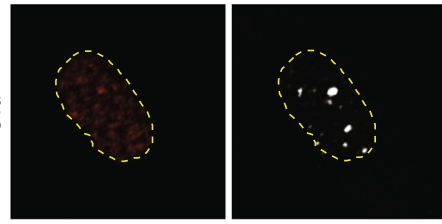

$\mathbf{e}$
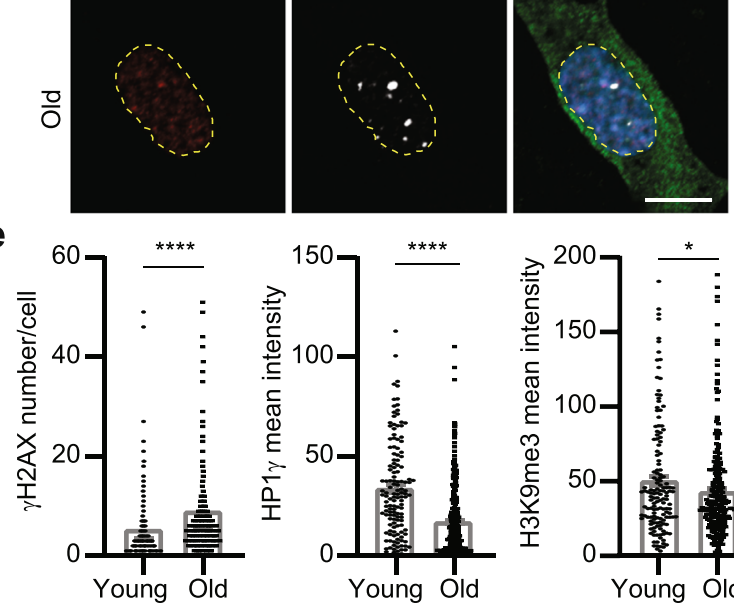

f
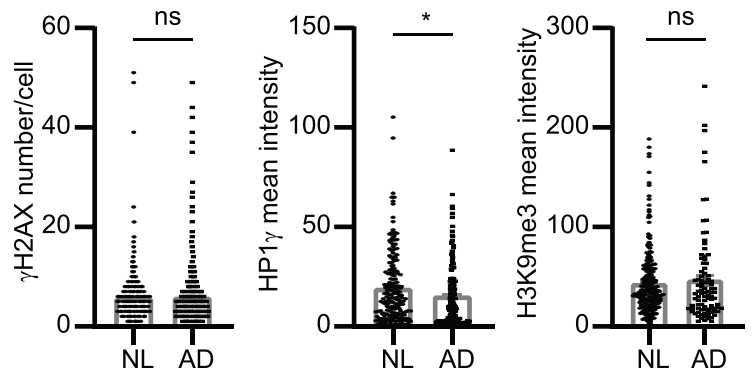

Fig. 3 hiBFCNs retain aging-associated features. a Conversion efficiency for the indicated human fibroblast samples analyzed at 14 dpi. hiBFCNs were derived from young (2-3 years) and old (47-79 years) samples and co-cultured with mouse astrocytes (mean $\pm \mathrm{SEM}$; $n=3717 \mathrm{GFP}^{+}$cells for Young samples; $n=10,323 \mathrm{GFP}^{+}$cells for NL samples; and $n=8752 \mathrm{GFP}^{+}$cells for AD samples). $\mathbf{b}$ Quantification of primary neurite numbers per neuron for the indicated samples at 51 dpi (mean \pm SEM; $n=361$ cells for Young and $n=1052$ for Old samples; $\left.{ }^{*} p=0.0175\right)$. c Primary neurite numbers per neuron for the indicated samples at $51 \mathrm{dpi}$ (mean $\pm \mathrm{SEM} ; n=875$ for $\mathrm{NL}$ and $n=538$ for AD samples; ns, not significant). $\mathbf{d}$ Representative confocal images for marker expression in the indicated samples co-cultured with astrocytes at $51 \mathrm{dpi}$. The profiles of DAPI ${ }^{+}$nuclei are outlined. Scale bar, $10 \mu \mathrm{m}$. e Quantifications of marker expression for the indicated young or old samples. Each dot represents a single cell (mean $\pm \mathrm{SEM} ; \mathrm{YH} 2 \mathrm{AX}$ : $n=426$ for Young, $n=1263$ for Old, ${ }^{* * *} p<0.0001$; HP1 $\gamma: n=139$ for Young, $n=421$ for Old, ${ }^{* * * *} p<0.0001$; H3K9me3: $n=146$ for Young, $n=243$ for Old; $\left.{ }^{*} p=0.0446\right)$. $\mathbf{f}$ Quantifications of marker expression for the indicated $\mathrm{NL}$ or $\mathrm{AD}$ samples. Each dot represents a single cell (mean \pm SEM; $Y H 2 A X: n=621$ for NL, $n=642$ for AD; HP1Y: $n=200$ for $\mathrm{NL}, n=221$ for $\mathrm{AD},{ }^{*} p=0.0162 ; \mathrm{H} 3 \mathrm{~K} 9 \mathrm{me} 3: n=243$ for $\mathrm{NL}, n=93$ for $A D ; n s$, not significant)

\section{Aging-associated TAU hyperphosphorylation in AD- hiBFCNs}

AD-related tauopathy arises early in BFCNs and parallels cognitive decline [44, 45]. We examined phosphorylated TAU through western blotting and immunocytochemistry by using the well-established AT8 antibody [46-50]. We used age- and gendermatched sample pairs cultured at the same time to reduce the potential influence of biological variabilities on phenotype. hiBFCNs were co-cultured with primary mouse astrocytes. When examined by western blotting at $28 \mathrm{dpi}$, no marked difference was observed for AT8 expression in NL- and AD-hiBFCNs (Additional file 4: Figure S4A). Since we failed to obtain enough hiBFCNs for western blotting at later culture time points, we focused our analysis on immunohistochemistry. When examined at $52 \mathrm{dpi}$ and compared to the control NL1-hiBFCNs (70 YR, female, APOE3/3), AD1-hiBFCNs (62 YR, female, APOE3/4) showed much elevated hyperphosphorylated TAU in the somas $(p=0.0004 ;$ Fig. $5 \mathrm{a}, \mathrm{b})$. Interestingly, this phenotype was delayed when comparing to another sample pair from younger individuals, NL2hiBFCNs (47 YR, male, APOE3/3) and AD2-hiBFCNs (47 YR, male, APOE3/4). The increased hyperphosphorylated TAU phenotype in AD2-hiBFCNs was not observed at the early time point 52 dpi (Fig. 5c, d); but it was evident at $62 \mathrm{dpi}$ and became even more significant at $78 \mathrm{dpi}(p=0.0298$ for $62 \mathrm{dpi}$ and $p=$ 0.0078 for $78 \mathrm{dpi}$; Fig. 5e-h). In contrast to the dysregulated TAU phosphorylation in somas, neuritic AT8 expression was similar in NL- and AD-hiBFCNs (Additional file 4: Figure S4B, C). 

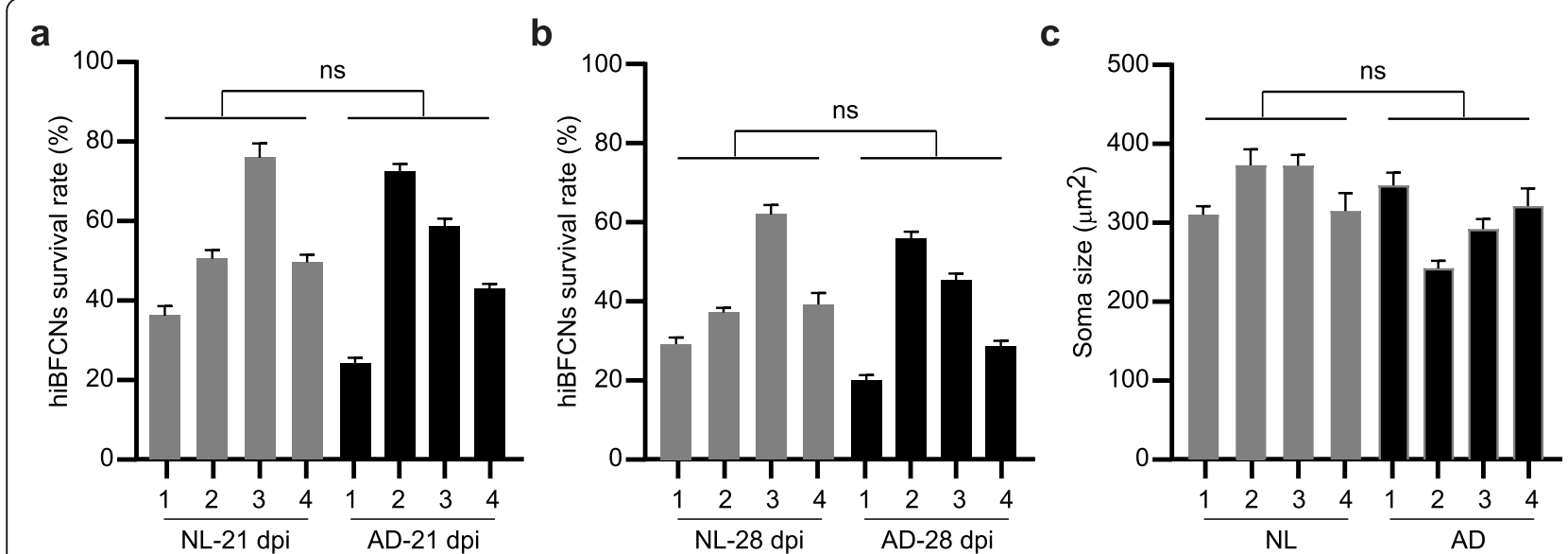

Fig. 4 Cell survival and soma size. a Survival of the indicated hiBFCNs assayed at $21 \mathrm{dpi}$ (mean \pm SEM; ns, not significant). $\mathbf{b}$ Survival of the indicated hiBFCNs assayed at $28 \mathrm{dpi}$ (mean \pm SEM; ns, not significant). c Quantification of soma size for the indicated hiBFCNs at $51 \mathrm{dpi}$ (mean \pm SEM; $n=192$ for NL1, $n=134$ for NL2, $n=216$ for NL3, $n=82$ for NL4, $n=178$ for AD1, $n=180$ for AD2, $n=220$ for AD3, and $n=69$ for AD4; ns, not significant)

\section{Time-dependent impairment of nucleocytoplasmic transport in AD-hiBFCNs}

TAU hyperphosphoration leads to disrupted nucleocytoplasmic transport (NCT) in AD neurons [51]. We examined NCT activity in hiBFCNs by using a wellestablished reporter assay [15, 51, 52]. This reporter (2Gi2R) consists of $2 x G F P$ containing an NES sequence (GFP-NES), an internal ribosome entry site (IRES), followed by $2 x R F P$ containing an NLS sequence (RFPNLS). GFP and RFP are localized in the cytoplasm and nucleus, respectively, in cells with normal NCT activity; however, such subcellular distribution of reporters will be disrupted in cells with abnormal NCT (Fig. 6a). A higher ratio of nuclear GFP to RFP $\left(\mathrm{GFP}_{\text {nuc }} / \mathrm{RFP}_{\text {nuc }}\right)$ represents disrupted NCT, whereas the nuclear to cytoplasmic GFP $\left(\mathrm{GFP}_{\text {nuc }} / \mathrm{GFP}_{\text {cyt }}\right)$ shows impaired protein export and a lower ratio of the nuclear to cytoplasmic RFP $\left(\mathrm{RFP}_{\text {nuc }} / \mathrm{RFP}_{\text {cyt }}\right)$ indicates compromised protein nuclear import.

The 2 Gi2R reporter was introduced into hiBFCNs during the initial reprogramming process. Neurons were cocultured with primary astrocytes until analysis by immunocytochemistry. Fluorescence intensity of the reporters in individual neurons was respectively measured in the nucleus or cytoplasm based on DAPI staining from confocal image sections. While no significant differences were observed between NL- and AD-hiBFCNs at the early $28 \mathrm{dpi}$ (Fig. 6b), AD-hiBFCNs showed markedly increased ratios of $\mathrm{GFP}_{\text {nuc }} / \mathrm{RFP}_{\text {nuc }}$ or $\mathrm{GFP}_{\text {nuc }} / \mathrm{GFP}_{\text {cyt }}$ when compared to the control NL group $(p=0.0309$ for $\mathrm{GFP}_{\text {nuc }} / \mathrm{RFP}_{\text {nuc }}$ and $p=0.0067$ for $\mathrm{GFP}_{\text {nuc }} / \mathrm{GFP}_{\text {cyt; }}$ Fig. $6 c, d)$. Conversely, the $R_{\text {FP }}$ nuc $/ \mathrm{RFP}_{\text {cyt }}$ ratios were significantly decreased in AD-hiBFCNs than the controls $(p<$ 0.0001 for $\mathrm{RFP}_{\text {nuc }} / \mathrm{RFP}_{\text {cyt }}$; Fig. 6c, d).To examine whether such dysregulated reporter distribution might be due to nuclear membrane breakdown, we treated 2Gi2Rexpressing hiBFCNs with leptomycin B (LMB), a potent and specific inhibitor of nuclear exports. Time-lapse live-cell confocal imaging and immunocytochemistry showed that both $\mathrm{NL}$ - and $\mathrm{AD}$-hiBFCNs robustly responded to LMB treatments, indicating that these cells had functional nuclear membranes (Additional file 5: Figure S5A-E). Together, these results indicate that ADhiBFCNs exhibit time-dependent impairments of NCT activities.

\section{Discussion}

BFCNs critically regulate brain function through projections to the cortex, hippocampus, and thalamus [1]. Their dysfunction is an early hallmark of AD [2, $3,53,54]$. Our direct induction of hiBFCNs from human patient fibroblasts provides a much-needed cell model to understand their molecular and cellular pathology in AD. These neurons retain certain agingassociated features that are critical to understating adult-onset neurodegenerative AD. Our proof-ofconcept study indeed reveals some potential defects in hiBFCNs from AD patients. These include timedependent TAU hyperphosphorylation and dysfunctional nucleocytoplasmic transport. Such preliminary results warrant future studies with additional patient samples. hiBFCNs especially those from AD patients may also be employed to screen or validate small molecules as therapeutics for AD.

The replacement of NEUROG2 with ASCL1 is critical for hiBFCNs, although both of them can work as pioneer factors during neuronal reprogramming of fibroblasts $[55,56]$. We previously demonstrated that human skin fibroblasts can be directly and efficiently converted into cholinergic neurons by the combined actions of 


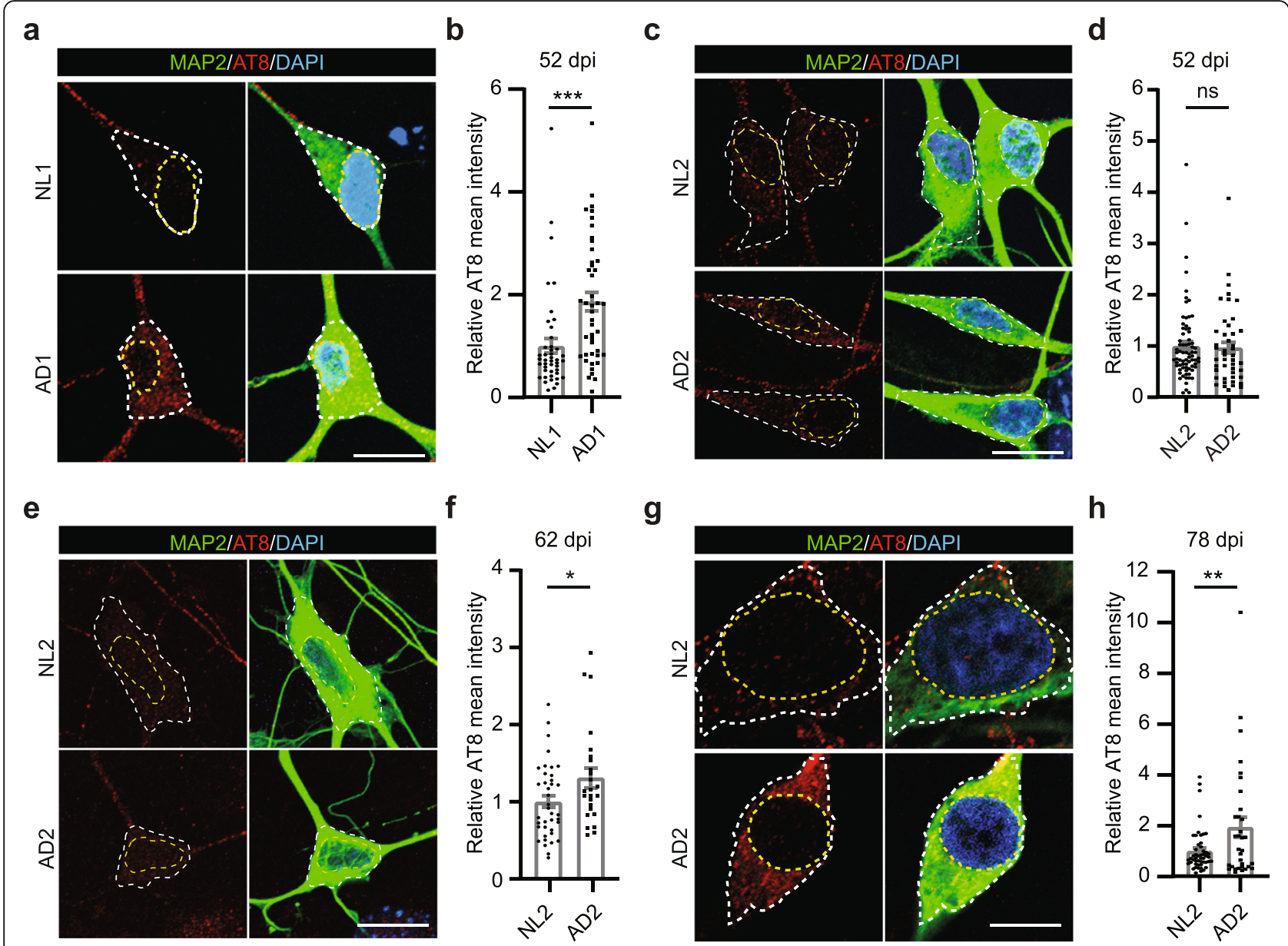

Fig. 5 Time-dependent TAU hyperphosphorylation. a Representative confocal images of marker expression in the indicated hiBFCNs at 52 dpi. Cell soma and nucleus are outlined, respectively. Scale bar, $10 \mu \mathrm{m}$. b Quantification of soma AT8 expression in the indicated hiBFCNs at $52 \mathrm{dpi}$. The dots indicate single cells (mean $\pm \mathrm{SEM} ; n=40$ for $\mathrm{NL} 1 ; n=41$ for $\mathrm{AD} 1 ;{ }^{* * *} p=0.0004$ ). $\mathbf{c}$ Representative confocal images of marker expression in the indicated hiBFCNs at $52 \mathrm{dpi}$. Scale bar, $10 \mu \mathrm{m}$. d Quantification of soma AT8 expression in the indicated hiBFCNs at $52 \mathrm{dpi}(\mathrm{mean} \pm \mathrm{SEM} ; n=66$ for NL2; $n=41$ for AD2; ns, not significant). e Representative confocal images of marker expression in the indicated hiBFCNs at $62 \mathrm{dpi}$. Scale bar, $10 \mu \mathrm{m}$. $\mathbf{f}$ Quantification of soma AT8 expression in the indicated hiBFCNs at $62 \mathrm{dpi}$ (mean $\pm \mathrm{SEM} ; n=39$ for NL2; $n=25$ for AD2; ${ }^{*} p=0.0298$ ). $\mathbf{g}$ Representative confocal images of marker expression in the indicated hiBFCNs at $78 \mathrm{dpi}$. Scale bar, $10 \mathrm{\mu m}$. $\mathbf{h}$ Quantification of soma AT8 expression in the indicated hiBFCNs at $78 \mathrm{dpi}$ (mean $\pm \mathrm{SEM} ; n=50$ for NL2; $n=30$ for $\mathrm{AD} 2 ;{ }^{*} p=0.0078$ )

NEUROG2, SOX11, and small molecules [18]. During the reprogramming process, NEUROG2 acts as a pioneer factor, whereas SOX11 facilitate fate transition and promote neuronal survival and maturation [18, 55]. Approximately $80 \%$ of the NEUROG 2 and SOX11-induced neurons are motor neuron-like with unique early expression of HB9, a key transcription factor restricted to spinal motor neurons [18]. These neurons can be further coerced into hiMNs with the inclusion of ISL1 and LHX3, two transcription factors critical for motor neuron development [57]. However, when we combined NEUROG2 and SOX11 with LHX8 and GBX1, two factors essential for BFCNs [7, 12, 22-26], $\mathrm{HB}^{+}$motor neuron-like cells were still observed. Such a result clearly shows a dominant role of NEUROG2 in motor neuron reprogramming. On the other hand, replacing NEUROG2 with ASCL1 completely eliminated generation of $\mathrm{HB}^{+}$cells and produced hiBFCNs.

Without passing through a pluripotent stem cell state, the direct reprogramming process for hiBFCNs is rapid and efficient. When examined at $28 \mathrm{dpi}$, more than $90 \%$ of those virus-transduced cells become neurons expressing stereotypical markers for BFCNs, such as CHAT, p75NTR, ISL1, and VACHT. qRT-PCR results further confirmed BFCN lineage. hiBFCNs become mature at $49 \mathrm{dpi}$ and beyond, showing typical inward sodium currents and outward potassium currents and firing repetitive APs when stimulated. They also show higher expression of L1CAM and exhibit more mature cell morphology at 78 dpi. 
a

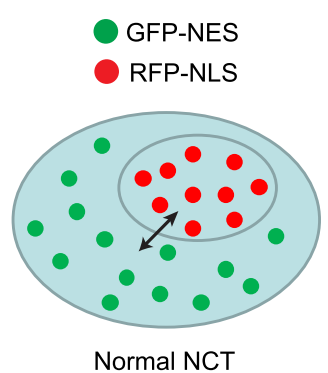

C

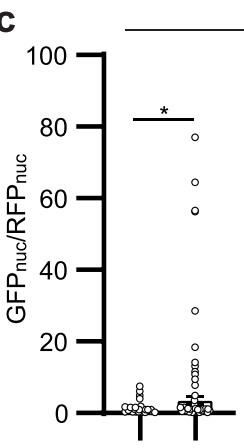

$\mathrm{NL} A D$

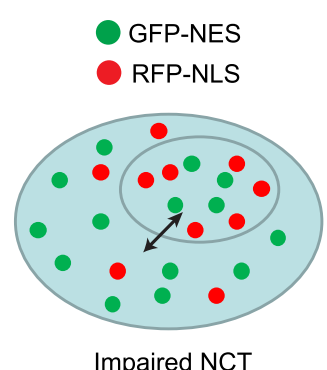

Impaired NCT b

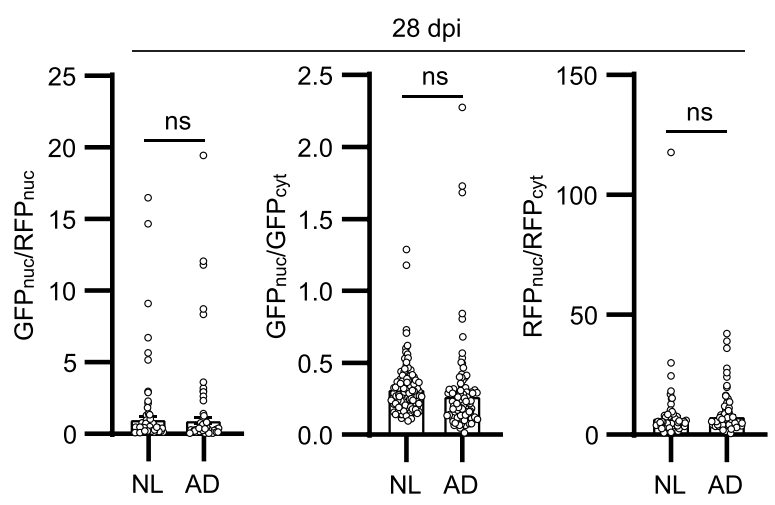

d

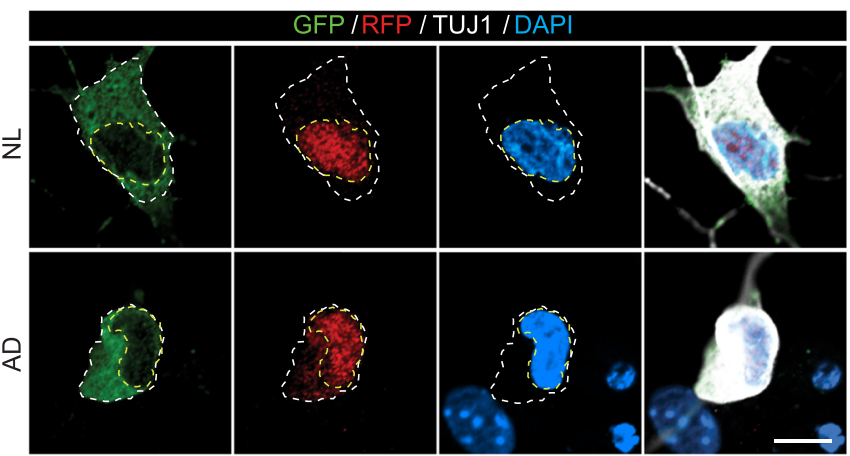

Fig. 6 Time-dependent impairment of nucleocytoplasmic transport activity in hiBFCNs. a A schematic of the reporter system for analyzing NCT activity. b Quantification of subcellular distributions of the reporters at 28 dpi. Each point represents a single cell (mean \pm SEM; $n=124$ for NL from 4 samples; $n=145$ for AD from 4 samples; ns, not significant). c Quantification of subcellular distributions of the reporters at 51 dpi. Each point represents a single cell (mean \pm SEM; $n=92$ for NL from 3 samples; $n=127$ for AD from 4 samples; ${ }^{*} p=0.0309,{ }^{* *} p=0.0067$, and ${ }^{* * * *} p<0.0001$ ). $\mathbf{d}$ Representative confocal images of reporter subcellular distributions in hiBFCNs at $51 \mathrm{dpi}$. Cell soma and nucleus are outlined. Scale bar, $10 \mu \mathrm{m}$

During early stage of the reprogramming process, cell death is a main reason causing neuronal loss. Cell death could be caused through apoptosis, necroptosis, and other pathways $[58,59]$. The replating step at $14 \mathrm{dpi}$, which is important for partial purification of the converted neurons, may also result in axotomy and subsequent axonal degeneration and cell death [59]. Interestingly, both NL- and AD-hiBFCNs respond similarly to the reprogramming process and the replating procedure, as we do not detect significant differences of cell survival or soma size before $28 \mathrm{dpi}$. Nonetheless, the reprogramming procedure may be further optimized for higher neuronal yield and purity in the future. Fibroblasts from different human patients also exhibit heterogeneity, which may lead to variable virus-transduction efficiency, cell survival, and neuronal yield.

We and others have recently demonstrated that directly induced neurons from adult human fibroblasts retain aging-associated signatures, which could be erased if passing through a pluripotent stem cell stage [15-17]. Some of these signatures include age-specific transcriptional and epigenetic profiles and age-dependent changes on DNA damage, chromatin structure, nuclear organization, and nucleocytoplasmic compartmentalization. Retaining these aging-associated features is critically important for understanding late-onset neurodegeneration such as $\mathrm{AD}$, since advanced age is the greatest known risk factor. Consistent with other directly induced neurons [14-17], our hiBFCNs also retain certain aging-associated signatures as their parental fibroblasts.

A disadvantage of directly induced neurons is their limited number and heterogeneity. Unlike ESCs or iPSCs which possess self-renewal ability, adult human fibroblasts become senescent after a limited number of passages. Directly induced neurons including hiBFCNs will be better suited for single cell analyses, such as immunocytochemistry, electrophysiology, and single-cell transcriptomics and genomics. Because long-term survival also requires co-culture with healthy astrocytes, hiBFCNs and some other directly converted neurons from adult human fibroblasts may not be well suited for biochemical analysis such as western and northern blotting. Directly induced neurons including hiBFCNs are also heterogeneous, since their parental fibroblasts cannot be single-cell cloned and be made isogenic through gene-editing. On the other hand, such heterogeneity may well resemble endogenous conditions in human patients. A good practice is to use age- and gender- 
matched sample pairs, as we have done in this proof-ofconcept study.

\section{Conclusions}

We established a protocol for the generation of aging relevant BFCNs from adult human skin fibroblasts including those of sporadic AD patients. To our knowledge, this is the first study in which direct lineage reprogramming bypasses pluripotency and converts fully differentiated adult somatic cells into electrophysiologically mature hiBFCNs. Our proof-of-concept study further reveals that hiBFCNs show promises as a cell model for understanding $\mathrm{AD}$ pathology, including tauopathy and nucleocytoplasmic transport dysfunction. The availability of these cells may also facilitate therapeutics identification for AD patients.

\section{Methods}

\section{Animals}

Wild-type C57BL/6 J mice were obtained from The Jackson Laboratory. All mice were housed under a controlled temperature and 12-h light/dark cycle with ad libitum access to food and water in the UT Southwestern animal facility. All experimental procedures and protocols were approved by the Institutional Animal Care and Use Committee at UT Southwestern.

\section{Plasmid construction and lentivirus preparation}

A third-generation, replication-deficient lentiviral vector ( $p$ CSC-SP-PW-IRES-GFP) was used to express NEUROG 2-IRES-GFP-T2A-Sox11, ASCL1-IRES-GFP-T2A-Sox11, ASCL1-IRES-Sox11, ISL1-T2A-LHX3, LHX8-T2A-GBX1, LHX8-IRES-GBX1, ASCL1-P2A-NEUROG2-IRES-Sox11. HEK293 cells (ATCC) were maintained in 10\% FBS DMEM medium (with $1 \%$ penicillin/streptomycin) with $5 \% \mathrm{CO}_{2}$ at $37^{\circ} \mathrm{C}$. HEK293 cells were seeded at $3 \times 10^{6}$ cells in $10 \mathrm{ml}$ medium per 10 -cm dish $24 \mathrm{~h}$ before transfection. Lentiviruses were generated in HEK293 cells by transient transfections with lentiviral vectors and the packaging plasmids ( $p M D L, V S V-G$ and $p R E V$ ) at a mass ratio of $4: 2: 1: 0.5$ ( $3 \mu \mathrm{l} \mathrm{PEI} / \mu \mathrm{g}$ plasmids) for thirdgeneration lentiviral vector (at $4 \mu \mathrm{g}: 2 \mu \mathrm{g}$ : $1 \mu \mathrm{g}$ : $0.5 \mu \mathrm{g}$ with $22.5 \mu \mathrm{l}$ PEI in $1 \mathrm{ml}$ DMEM for $10-\mathrm{cm}$ dish). The $2 G i 2 R$ lentivirus was generated in HEK293 cells by transient transfections with lenti XEP.2GFP:NES-IRES-2RFP: $N L S$ and the packaging plasmids (psPAX2 and $V S V-G$ ) at a mass ratio of 2:2:1 (3 $\mu \mathrm{l} \mathrm{PEI} / \mu \mathrm{g}$ plasmids) (at $10 \mu \mathrm{g}$ : $10 \mu \mathrm{g}$ : $5 \mu \mathrm{g}$ with $75 \mu \mathrm{l}$ PEI in $1 \mathrm{ml}$ DMEM for $10-\mathrm{cm}$ dish). The mixture was incubated for $15 \mathrm{~min}$ at RT before adding to the culture. Medium was refreshed after $12 \mathrm{~h}$ to $15 \mathrm{~h}$ incubation. Viruses were collected at $24 \mathrm{~h}$ and refreshed with new medium again for one more collection at $48 \mathrm{~h}$. These two collections were combined. Lentiviral supernatants were cleared with $0.45 \mu \mathrm{m}$ filter and stored at $4{ }^{\circ} \mathrm{C}$ prior to cell transduction.

\section{Human fibroblast culture}

All human fibroblasts from either healthy controls or sporadic $\mathrm{AD}$ patients with different $A P O E$ alleles were purchased from the Coriell Institute for Medical Research (Table 1). They were maintained in Fibroblast Medium (DMEM containing 15\% FBS and 1\% penicillin/ streptomycin) with $5 \% \mathrm{CO}_{2}$ at $37^{\circ} \mathrm{C}$.

\section{Neuron induction and culture}

Direct lineage reprogramming was conducted according to a previous protocol with some modifications $[18,19]$. In brief, fibroblasts were seeded onto Matrigel-coated culture vessels $\left(4.8 \times 10^{5}\right.$ cells per 24 - or 48 -well plate or $3 \times 10^{5}$ cells per 6 -cm dish or $1 \times 10^{6}$ cells per $10-\mathrm{cm}$ dish) and cultured in Fibroblast Medium for 1 day. Then, cells were transduced with lentiviral supernatants in the presence of $8 \mu \mathrm{g} / \mathrm{ml}$ polybrene. Fibroblast culture medium was refreshed after overnight incubation. One day later, these cells were switched into Reprogramming Medium (C2 medium supplemented with $10 \mu \mathrm{M}$ FSK (Sigma-Aldrich), $1 \mu \mathrm{M}$ LDN-193189 (EMD Millipore), and $10 \mathrm{ng} / \mathrm{ml}$ FGF2 (PeproTech)). The C2 medium was

Table 1 Human fibroblasts used in this study

\begin{tabular}{|c|c|c|c|c|c|c|c|}
\hline Sample Name & Company & Catalog ID & Origin & Age & Gender & Disease & APOE isoforms \\
\hline$Y-1$ & Coriell & GM00969 & Skin & 2 Years & Female & Apparently Healthy & - \\
\hline$Y-2$ & Coriell & GM05565 & Skin & 3 Years & Male & Apparently Healthy & - \\
\hline NL1 & Coriell & AG11733 & Skin & 70 Years & Female & Apparently Healthy & $\varepsilon 3 / 3$ \\
\hline $\mathrm{NL} 2$ & Coriell & AG12989 & Skin & 47 Years & Male & Apparently Healthy & $\varepsilon 3 / 3$ \\
\hline NL3 & Coriell & AG07479 & Skin & 70 Years & Female & Apparently Healthy & - \\
\hline $\mathrm{NL} 4$ & Coriell & AG12934 & Skin & 77 Years & Male & Apparently Healthy & $\varepsilon 3 / 3$ \\
\hline AD1 & Coriell & AG06264 & Skin & 62 Years & Female & $A D$ & $\varepsilon 3 / 4$ \\
\hline AD2 & Coriell & AG04402 & Skin & 47 Years & Male & $A D$ & $\varepsilon 3 / 4$ \\
\hline AD3 & Coriell & AG21158 & Skin & 69 Years & Female & $A D$ & $\varepsilon 2 / 3$ \\
\hline AD4 & Coriell & AG05810 & Skin & 79 Years & Male & $A D$ & $\varepsilon 3 / 4$ \\
\hline
\end{tabular}


composed of DMEM:F12:neurobasal (1:1:1), $0.8 \%$ N2 (Invitrogen), 0.8\% B27 (Invitrogen), and 1\% penicillin/ streptomycin. The Reprogramming Medium was half changed every other day until $14 \mathrm{dpi}$. These cells were dissociated with $0.05 \%$ trypsin for $3 \mathrm{~min}$ at $37^{\circ} \mathrm{C}$ and resuspended in Fibroblast Medium to quench trypsin activity. This cell suspension was then plated into a $0.1 \%$ gelatin-coated culture dish on which contaminating fibroblasts could tightly attach. About one and a half hours later, floating cells, which mainly consisted of induced neurons, were collected by centrifugation at $400 \mathrm{~g}$ for $3 \mathrm{~min}$. Cells were resuspended into $\mathrm{C} 2$ medium and centrifuged again to remove cell debris. Finally, induced neurons were plated into primary astrocytes-coated plates in Maturation Medium (C2 medium supplemented with $5 \mu \mathrm{M}$ FSK, $10 \mathrm{ng} / \mathrm{ml}$ each of BDNF, GDNF, and NT3 (PeproTech), $50 \mathrm{ng} / \mathrm{ml}$ NGF $\beta$ (PeproTech)). Unless indicated otherwise, Maturation Medium was half changed twice a week. For conversion efficiency calculation, induced neurons were plated into primary astrocytes-coated 96-well plates (at least three wells per condition). Fourteen days after replating (at $28 \mathrm{dpi}$ ) in maturation medium, cells were fixed and stained with antibodies for GFP, TUJ1, CHAT, or ISL1. Nuclei were counterstained with DAPI. The percentage of $\mathrm{TUJ}^{+} \mathrm{GFP}^{+}$cells among total $\mathrm{GFP}^{+}$cells was calculated as conversion efficiency. The percentage of $\mathrm{CHAT}^{+-}$ $\mathrm{TUJ}^{+}$among $\mathrm{TUJ}^{+}$cells was calculated as conversion purity. The percentage of $\mathrm{CHAT}^{+}$or ISL $1^{+}$cells among total $\mathrm{GFP}^{+}$cells was also calculated. Human induced motor neurons (hiMNs) were generated essentially as described previously [19].

\section{Immunocytochemistry}

Cell cultures at the indicated time points were fixed with 4\% paraformaldehyde (PFA) in PBS for $15 \mathrm{~min}$ at room temperature, twice-washed with PBS, and then permeabilized/blocked for $1 \mathrm{~h}$ in blocking solution (1 x PBS containing $0.2 \%$ Triton X-100 and 3\% BSA). Primary antibodies (Table S1) in blocking solution were then added and incubated overnight at $4{ }^{\circ} \mathrm{C}$, followed by PBS washing and incubation with Alexa Fluor-conjugated corresponding secondary antibodies made in donkey (Invitrogen, 1:500). Images were obtained with a NIKON A1R confocal microscope. The mean fluorescence intensity of AT8 staining in the cytosol or neurites of each neuron was quantified using Image J.

\section{Cell survival analysis}

hiBFCNs co-cultured with primary mouse astrocytes were used for survival analysis. Cortical astrocytes were prepared as previously described with modifications [20]. Briefly, cortices were dissociated with a solution containing papain $\left(10 \mathrm{U} / \mathrm{ml}\right.$, with $1 \mathrm{mM} \mathrm{Ca}{ }^{2+}$ and $0.5 \mathrm{mM}$
EDTA) and $1 \%$ DNase for $20 \mathrm{~min}$ at $37^{\circ} \mathrm{C}$. Tissues were pelleted through brief centrifugation and further dissociated using a pipette in FBS-containing medium. Cells were passed through a $40 \mu \mathrm{m}$ nylon strainer. The cell mixture was spun at $400 \mathrm{~g}$ for $3 \mathrm{~min}$ and re-suspended in growth media consisting of DMEM (Invitrogen) supplemented with $10 \%$ FBS and plated into $0.1 \%$ gelatin coated $75 \mathrm{~cm}^{2}$ flasks. Media was exchanged every 3 days. Endogenous mouse neurons and non-astrocytes were removed by vigorous shaking and a few cycles of passaging, freezing, thawing, and replating. hiBFCNs at $14 \mathrm{dpi}$ were replated into astrocyte-coated 96-well plates (survival analysis) or coverslip-containing 24-well plates (for neuronal morphology analysis). Co-cultures were fed twice a week with Maturation Medium. Under an AMG EVOS digital inverted fluorescence microscope, $\mathrm{TUJ}^{+} \mathrm{GFP}^{+}$cells within the entire well of a 96-well plate in triplicate were quantified by a researcher blinded to experimental groups. Cell counts were normalized to the starting number of cells plated into each well. Survival rate at $14 \mathrm{dpi}$ for each cell line was set as $100 \%$, to which the subsequent survived cells at each time point were normalized.

\section{Quantitative RT-PCR (qRT-PCR)}

hiBFCNs and hiMNs were cultured in Matrigel-coated plates until the indicated time point. They were then resuspended through gentle pipetting with $0.5 \sim 1 \mathrm{ml}$ culture medium to partially remove contaminating fibroblasts. Cells were pelleted by $800 \mathrm{~g} \times 5 \mathrm{~min}$ at $4{ }^{\circ} \mathrm{C}$ and lysed in TRIzol reagent (Invitrogen). Total RNA was isolated by using a commercial kit (RNA Clean \& Concentrator kits, ZYMO Research). Human brain total RNA was purchased from Clontech (Cat\#: 636530). cDNA was synthesized from total RNA (50 $100 \mathrm{ng}$ per sample) with the SuperScriptIII First-Strand Synthesis kit (Invitrogen). Real-Time PCR was performed with the SYBR GreenER SuperMix (Invitrogen) on the QuantStudio 5 Real-Time PCR System (Thermo Fisher). Primer sequences are listed in Supplementary Table S2 and their quality was assessed by the dissociation curve. Relative gene expression was determined by using the $2^{-\triangle \Delta \mathrm{Ct}}$ method after normalization to the loading control GAPDH.

\section{Nucleocytoplasmic transport}

The 2Gi2R reporter-expressing lentivirus was included during the reprogramming of fibroblasts to hiBFCNs. Cells were replated onto astrocyte-coated and Matrigeltreated coverslips. At the indicated time points, cells were fixed with $4 \%$ PFA, followed by immunostaining with antibodies against GFP, RFP, and TUJ1. Nuclei were counterstained with DAPI. For live-cell imaging, cells at the indicated time point were maintained at 
$37{ }^{\circ} \mathrm{C}$ with $5 \% \mathrm{CO}_{2}$ under the Nikon A1R confocal microscope system. The target cells were located under a 60x objective and imaged as $0 \mathrm{~min}$. Culture medium was then replaced with prewarmed medium containing $50 \mathrm{nM}$ leptomycin B (LMB). Cells were subsequently imaged every $10 \mathrm{~min}$ for a total of $1 \mathrm{~h}$, followed by fixation with $4 \%$ PFA and immunocytochemistry. Images of single confocal plane across the center of the nucleus were obtained on the NIKON A1R confocal microscope with a pinhole setting at 2.5 . Because of the complexity of neuron-astrocyte co-cultures, neuronal nucleus and soma were manually defined by using the Image J program. The mean fluorescence intensity of GFP or RFP was separately measured in the cytoplasm or nucleus of hiBFCNs. The ratios of $\mathrm{GFP}_{\text {nuc }} / \mathrm{RFP}_{\text {nuc }}, \mathrm{GFP}_{\text {nuc }} / \mathrm{GFP}_{\text {cyt }}$ and $R_{\text {neP }} / \mathrm{RFP}_{\text {cyt }}$ were calculated by Microsoft Excel and analyzed by GraphPad Prism 8 .

\section{Western blotting}

hiBFCNs were co-cultured with astrocytes in Matrigelcoated plates. As controls, generic human induced neurons (hiNs) were produced through reprogramming adult skin fibroblasts with the lentivirus expressing ASCL1-P2A-NEUROG2-IRES-Sox11. Reprogramming Medium (C2 medium supplemented with $5 \mu \mathrm{M}$ FSK (Sigma-Aldrich), $1 \mu \mathrm{M}$ LDN-193189 (EMD Millipore), $1 \mu \mathrm{M}$ Dorsomorphin (EMD Millipore), $0.5 \mu \mathrm{M}$ A83-1 (Tocris), $3 \mu \mathrm{M}$ CHIR99021 (Selleckchem), $10 \mu \mathrm{M}$ SB431542 (Selleckchem), $1 \mu \mathrm{g} / \mathrm{ml}$ laminin (Corning) and $10 \mathrm{ng} / \mathrm{ml} \mathrm{FGF2} \mathrm{(PeproTech))} \mathrm{was} \mathrm{used} \mathrm{for} \mathrm{hiNs} \mathrm{induc-}$ tion. hiNs were replated into Matrigel-coated plates at 16 dpi. Cells were maintained in Maturation Medium (C2 medium supplemented with $5 \mu \mathrm{M}$ FSK, $10 \mathrm{ng} / \mathrm{ml}$ each of BDNF, GDNF, and NT3 (PeproTech)). At the indicated time points, cells were collected and lysed in buffer composed of $50 \mathrm{mM}$ Tris- $\mathrm{HCl}$ buffer ( $\mathrm{pH} 7.5$ ), $150 \mathrm{mM} \mathrm{NaCl}, 1 \%$ Triton X-100, 0.1\% SDS, $0.5 \%$ sodium deoxycholate, protease inhibitors (Pierce), and PhosSTOP (Roche). Protein concentration was measured by the Bradford assay. Protein samples were separated by 12\% SDS-PAGE and transferred to PVDF membranes. After blocking in 5\% nonfat milk in PBST for $1 \mathrm{~h}$ at room temperature, membranes were incubated overnight with primary antibodies at $4{ }^{\circ} \mathrm{C}$. Horseradish peroxidase-conjugated secondary antibodies (Jackson) were applied, and the blots were developed with Pierce ECL Western Blotting Substrate (Thermo-Fisher) or Immobilon Western Chemiluminescent HRP substrate (Millipore-Sigma). Antibodies are listed in Table S1.

\section{Electrophysiology}

Whole-cell patch-clamp recordings were made under visual guidance using infra-red differential interference contrast (IR-DIC) and GFP fluorescence to identify
$\mathrm{GFP}^{+}$cells. For analysis of intrinsic neuronal properties, cells were maintained at $30^{\circ} \mathrm{C}$ in a submersion chamber with Tyrode solution containing $150 \mathrm{mM} \mathrm{NaCl}, 4 \mathrm{mM}$ $\mathrm{KCl}, 2 \mathrm{mM} \mathrm{MgCl}, 3 \mathrm{mM} \mathrm{CaCl}_{2}, 10 \mathrm{mM}$ glucose, and 10 $\mathrm{mM}$ HEPES at $\mathrm{pH} 7.4$ (adjusted with $\mathrm{KOH}$ ) and 300 mOsm. Whole-cell recordings were performed on induced neurons using recording pipettes (approximately 5-9 $\mathrm{M} \Omega$ ) filled with intracellular solution $(0.2 \mathrm{mM}$ EGTA, $130 \mathrm{mM} \mathrm{K-Gluconate,} 6 \mathrm{mM} \mathrm{KCl}, 3 \mathrm{mM} \mathrm{NaCl}$, $10 \mathrm{mM}$ HEPES, $4 \mathrm{mM}$ ATG-Mg, $0.4 \mathrm{mM}$ GTP-Na, 14 $\mathrm{mM}$ phosphocreatine-di(Tris) at $\mathrm{pH} 7.2$ (adjusted by $\mathrm{KOH})$ and $285 \mathrm{mOsm}$ ). Series and input resistance were measured in voltage-clamp mode with a $400 \mathrm{~ms}, 10 \mathrm{mV}$ step from a $-60 \mathrm{mV}$ holding potential (filtered at 10 $\mathrm{kHz}$, sampled at $50 \mathrm{kHz}$ ). Cells were only accepted for analysis if the series resistance was less than $30 \mathrm{M} \Omega$ and stable $(<10 \%$ change) throughout the experiment. Input resistance ranged from 0.2 to $2 \mathrm{G} \Omega$. Currents were filtered at $3 \mathrm{kHz}$, acquired and digitized at $10 \mathrm{kHz}$ on a $\mathrm{PC}$ using Clampex10.3 software (Molecular Devices). A MultiClamp 700B amplifier (Molecular Devices, Palo Alto, CA) was used for recordings.

Action potentials were recorded in current clamp mode and elicited by a series of current injections starting from -20 to $200 \mathrm{pA}$ with $20-\mathrm{pA}$ increments and $800-\mathrm{ms}$ in duration. Sodium and potassium currents were recorded in voltage-clamp mode in response to a series of voltage steps ranging from -60 to $+60 \mathrm{mV}$ at $10-\mathrm{mV}$ increments and 250-ms duration according to standard protocols. Sag voltage was recorded in currentclamp mode with hyperpolarizing current $(-80$ to -150 $\mathrm{pA}, 500 \mathrm{~ms}) . I_{h}$ was recorded in voltage-clamp mode by injecting voltage steps from -110 to $-40 \mathrm{mV}$ with 10 $\mathrm{mV}$ increments for $6 \mathrm{~s}$ duration, and an average of 10 traces. In all voltage-clamp recordings, cells were clamped at $-60 \mathrm{mV}$ except during the voltage-step protocol. In all current-clamp recordings, recordings were made at resting membrane potential or without any current injection except otherwise stated.

Data analysis was performed using Clamp-fit 10.3 software (Molecular Devices). The action potential (AP) was analyzed as described previously [19]. The AP trace immediately above threshold was used to determine the delay of 1 st spike as the length of time from the start of current steps to the peak of AP. The same AP trace was used to measure AP threshold as the corresponding voltage when there was the sharpest change of trace slope. The above-indicated AP trace was also used to determine AP amplitude, halfwidth, maximum velocity of rise, and decay slope using the "Statistics" function from the "Analyze" menu. AP frequency was obtained by dividing the maximum number of spikes during the current steps protocol with the step time duration $(800 \mathrm{~ms})$. 
Similarly, sodium and potassium currents were measured using the "Statistics" function. The biggest current was used.

\section{Statistical analysis}

All experiments were performed at least twice in triplicate unless otherwise indicated. Data were presented as mean \pm SEM. One-way ANOVA or unpaired Student's ttest was used to calculate statistical significance in GraphPad Prism. Significant differences are indicated by " $p<0.05$, "** $p<0.01$, **** $p<0.001$, and ${ }^{* * * * *} p<0.0001$.

\section{Supplementary information}

Supplementary information accompanies this paper at https://doi.org/10. 1186/s13024-020-00411-6.

Additional file 1: Figure S1. The reprogramming process and optimization, related to Fig. $1 \mathrm{~A}$.

Additional file 2: Figure S2. Characterization of the induced neurons, related to Fig. $1 \mathrm{~A}$.

Additional file 3: Figure S3. Characterization of AD-hiBFCNs, related to Fig. 1 A

Additional file 4: Figure S4. PhosphoTAU expression in hiBFCNs, related to Fig. $5 \mathrm{~A}$.

Additional file 5: Figure S5. Effect of $L M B$ on nucleocytoplasmic transport in hiBFCNs, related to Fig. 6 A.

Additional file 6: Table S1. Primary antibodies. Table S2. Primer sequences

\section{Abbreviations}

AD: Alzheimer's disease; APs: Action potentials; APOE: Apolipoprotein E; BFCNs: Basal forebrain cholinergic neurons; CHAT: Choline acetyltransferase; FGF2: Fibroblast growth factor beta; FSK: Forskolin; $I_{A}$ : A-type potassium current; $l_{d}$ : Delayed-rectifier potassium current; $l_{h}$ : Hyperpolarization-activated current; $I_{\text {Na: }}$ Sodium current; MNs: Motor neurons; NL: Normal line; NF200: Neurofilament 200; qRT-PCR: Quantitative RT-PCR; SYN1: Synapsin 1; VACHT: Vesicular acetylcholine transporter

\section{Acknowledgments}

We thank members of the C.-L.Z. laboratory for discussions and reagents. C.L.Z. is a W.W. Caruth, Jr. Scholar in Biomedical Research and supported by the Welch Foundation (I-1724), the Decherd Foundation, Kent Waldrep Foundation Center for Basic Research on Nerve Growth and Regeneration, and NIH Grants (NS099073, NS092616, NS111776, NS117065 and NS088095).

\section{Authors' contributions}

S.M., T.Z., M.-L.L. and C.-L.Z. conceived and designed the experiment. S.M., T.Z., M.-L.L. performed experiments related to molecular and cellular biology. T.Z. conducted all experiments related to electrophysiology. S.M. and T.Z. created figures for the manuscript. S.M., T.Z., and C.-L.Z. analyzed data and prepared the manuscript. All authors reviewed and approved the final manuscript.

\section{Availability of data and materials}

All data generated or analyzed during this study are included in the article and its supplementary information files.

\section{Ethics approval and consent to participate}

This study was approved by Institutional Animal Care and Use Committee at UT Southwestern Medical Center.

\section{Consent for publication}

Not applicable.

\section{Competing interests}

The authors do not have competing interests in the manuscript.

Received: 15 May 2020 Accepted: 7 October 2020

Published online: 21 October 2020

\section{References}

1. Mesulam MM, Mufson EJ, Wainer BH, Levey Al. Central cholinergic pathways in the rat: an overview based on an alternative nomenclature (Ch1-Ch6). Neuroscience. 1983;10:1185-201.

2. Whitehouse PJ, Price DL, Struble RG, Clark AW, Coyle JT, Delon MR. Alzheimer's disease and senile dementia: loss of neurons in the basal forebrain. Science. 1982;215:1237-9.

3. Coyle JT, Price DL, DeLong MR. Alzheimer's disease: a disorder of cortical cholinergic innervation. Science. 1983;219:1184-90.

4. Yue W, Li Y, Zhang T, Jiang M, Qian Y, Zhang M, Sheng N, Feng S, Tang K, Yu X, et al. ESC-derived basal forebrain cholinergic neurons ameliorate the cognitive symptoms associated with Alzheimer's disease in mouse models. Stem Cell Reports. 2015;5:776-90.

5. Liu Y, Weick JP, Liu H, Krencik R, Zhang X, Ma L, Zhou GM, Ayala M, Zhang SC. Medial ganglionic eminence-like cells derived from human embryonic stem cells correct learning and memory deficits. Nat Biotechnol. 2013;31:440-7.

6. Kwakowsky A, Potapov K, Kim S, Peppercorn K, Tate WP, Abraham IM Treatment of beta amyloid 1-42 (Abeta(1-42))-induced basal forebrain cholinergic damage by a non-classical estrogen signaling activator in vivo. Sci Rep. 2016;6:21101.

7. Bissonnette CJ, Lyass L, Bhattacharyya BJ, Belmadani A, Miller RJ, Kessler JA. The controlled generation of functional basal forebrain cholinergic neurons from human embryonic stem cells. Stem Cells. 2011;29:802-11.

8. Wicklund L, Leao RN, Stromberg AM, Mousavi M, Hovatta O, Nordberg A, Marutle A. Beta-amyloid 1-42 oligomers impair function of human embryonic stem cell-derived forebrain cholinergic neurons. PLoS One. 2010; 5:e15600.

9. Moreno CL, Della Guardia L, Shnyder V, Ortiz-Virumbrales M, Kruglikov I, Zhang B, Schadt EE, Tanzi RE, Noggle S, Buettner C, Gandy S. iPSC-derived familial Alzheimer's PSEN2 (N141I) cholinergic neurons exhibit mutationdependent molecular pathology corrected by insulin signaling. Mol Neurodegener. 2018:13:33

10. Hu Y, Qu ZY, Cao SY, Li Q, Ma L, Krencik R, Xu M, Liu Y. Directed differentiation of basal forebrain cholinergic neurons from human pluripotent stem cells. J Neurosci Methods. 2016;266:42-9.

11. Duan L, Bhattacharyya BJ, Belmadani A, Pan L, Miller RJ, Kessler JA. Stem cell derived basal forebrain cholinergic neurons from Alzheimer's disease patients are more susceptible to cell death. Mol Neurodegener. 2014;9:3.

12. Crompton LA, Byrne ML, Taylor H, Kerrigan TL, Bru-Mercier G, Badger JL, Barbuti PA, Jo J, Tyler SJ, Allen SJ, et al. Stepwise, non-adherent differentiation of human pluripotent stem cells to generate basal forebrain cholinergic neurons via hedgehog signaling. Stem Cell Res. 2013;11:1206-21.

13. Ortiz-Virumbrales M, Moreno CL, Kruglikov I, Marazuela P, Sproul A, Jacob S, Zimmer M, Paull D, Zhang B, Schadt EE, et al. CRISPR/Cas9-correctable mutation-related molecular and physiological phenotypes in iPSC-derived Alzheimer's PSEN2 (N141I) neurons. Acta Neuropathol Commun. 2017:5:77.

14. Mertens J, Reid D, Lau S, Kim Y, Gage FH. Aging in a dish: iPSC-derived and directly induced neurons for studying brain aging and age-related neurodegenerative diseases. Annu Rev Genet. 2018;52:271-93.

15. Mertens J, Paquola ACM, Ku M, Hatch E, Bohnke L, Ladjevardi S, McGrath S, Campbell B, Lee H, Herdy JR, et al. Directly reprogrammed human neurons retain aging-associated Transcriptomic signatures and reveal age-related Nucleocytoplasmic defects. Cell Stem Cell. 2015;17:705-18.

16. Tang Y, Liu ML, Zang T, Zhang CL. Direct reprogramming rather than iPSCbased reprogramming maintains aging hallmarks in human motor neurons. Front Mol Neurosci. 2017;10:359.

17. Huh CJ, Zhang B, Victor MB, Dahiya S, Batista LF, Horvath S, Yoo AS. Maintenance of age in human neurons generated by microRNA-based neuronal conversion of fibroblasts. Elife. 2016:5:e18648.

18. Liu ML, Zang T, Zou Y, Chang JC, Gibson JR, Huber KM, Zhang CL. Small molecules enable neurogenin 2 to efficiently convert human fibroblasts into cholinergic neurons. Nat Commun. 2013:4:2183. 
19. Liu ML, Zang T, Zhang CL. Direct lineage reprogramming reveals diseasespecific phenotypes of motor neurons from human ALS patients. Cell Rep. 2016;14:115-28.

20. Vierbuchen T, Ostermeier A, Pang ZP, Kokubu Y, Sudhof TC, Wernig M. Direct conversion of fibroblasts to functional neurons by defined factors. Nature. 2010:463:1035-41.

21. Matsumoto K, Tanaka T, Furuyama T, Kashihara Y, Mori T, Ishii N, Kitanaka J, Takemura M, Tohyama M, Wanaka A. L3, a novel murine LIM-homeodomain transcription factor expressed in the ventral telencephalon and the mesenchyme surrounding the oral cavity. Neurosci Lett. 1996;204:113-6.

22. Mori T, Yuxing Z, Takaki H, Takeuchi M, Iseki K, Hagino S, Kitanaka J, Takemura M, Misawa H, Ikawa M, et al. The LIM homeobox gene, L3/Lhx8, is necessary for proper development of basal forebrain cholinergic neurons. Eur J Neurosci. 2004;19:3129-41.

23. Asbreuk $\mathrm{CH}$, van Schaick HS, Cox JJ, Kromkamp M, Smidt MP, Burbach JP. The homeobox genes $\operatorname{Lhx} 7$ and Gbx1 are expressed in the basal forebrain cholinergic system. Neuroscience. 2002;109:287-98.

24. Manabe $T$, Tatsumi $K$, Inoue M, Makinodan M, Yamauchi T, Makinodan E, Yokoyama S, Sakumura R, Wanaka A. L3/Lhx8 is a pivotal factor for cholinergic differentiation of murine embryonic stem cells. Cell Death Differ. 2007; 14:1080-5.

25. Zhao Y, Marin O, Hermesz E, Powell A, Flames N, Palkovits M, Rubenstein JL, Westphal $\mathrm{H}$. The LIM-homeobox gene Lhx8 is required for the development of many cholinergic neurons in the mouse forebrain. Proc Natl Acad Sci U S A. 2003;100:9005-10

26. Fragkouli A, Hearn C, Errington M, Cooke S, Grigoriou M, Bliss T, Stylianopoulou F, Pachnis V. Loss of forebrain cholinergic neurons and impairment in spatial learning and memory in LHX7-deficient mice. Eur J Neurosci. 2005;21:2923-38

27. Ma YC, Song MR, Park JP, Henry Ho HY, Hu L, Kurtev MV, Zieg J, Ma Q, Pfaff $S L$, Greenberg ME. Regulation of motor neuron specification by phosphorylation of neurogenin 2. Neuron. 2008;58:65-77.

28. Mizuguchi R, Sugimori M, Takebayashi H, Kosako H, Nagao M, Yoshida S, Nabeshima Y, Shimamura K, Nakafuku M. Combinatorial roles of olig2 and neurogenin2 in the coordinated induction of pan-neuronal and subtypespecific properties of motoneurons. Neuron. 2001:31:757-71.

29. Herdy J, Schafer S, Kim Y, Ansari Z, Zangwill D, Ku M, Paquola A, Lee H, Mertens J, Gage FH. Chemical modulation of transcriptionally enriched signaling pathways to optimize the conversion of fibroblasts into neurons. Elife. 2019:8:e41356.

30. Ladewig J, Mertens J, Kesavan J, Doerr J, Poppe D, Glaue F, Herms S, Wernet $P$, Kogler G, Muller FJ, et al. Small molecules enable highly efficient neuronal conversion of human fibroblasts. Nat Methods. 2012;9:575-8.

31. Kim EJ, Battiste J, Nakagawa Y, Johnson JE. Ascl1 (Mash1) lineage cells contribute to discrete cell populations in CNS architecture. Mol Cell Neurosci. 2008;38:595-606.

32. Marin O, Anderson SA, Rubenstein JL. Origin and molecular specification of striatal interneurons. J Neurosci. 2000;20:6063-76.

33. Liang XG, Tan C, Wang CK, Tao RR, Huang YJ, Ma KF, Fukunaga K, Huang MZ, Han F. Myt1l induced direct reprogramming of pericytes into cholinergic neurons. CNS Neurosci Ther. 2018;24:801-9.

34. Vetreno RP, Crews FT. Adolescent binge ethanol-induced loss of basal forebrain cholinergic neurons and neuroimmune activation are prevented by exercise and indomethacin. PLoS One. 2018;13:e0204500.

35. Insua D, Corredoira A, Gonzalez-Martinez A, Suarez ML, Santamarina G, Sarasa M, Pesini P. Expression of p75(NTR), a marker for basal forebrain cholinergic neurons, in young and aged dogs with or without cognitive dysfunction syndrome. J Alzheimers Dis. 2012;28:291-6.

36. Yeo TT, Chua-Couzens J, Butcher LL, Bredesen DE, Cooper JD, Valletta JS, Mobley WC, Longo FM. Absence of p75NTR causes increased basal forebrain cholinergic neuron size, choline acetyltransferase activity, and target innervation. J Neurosci. 1997;17:7594-605.

37. Mufson EJ, Ginsberg SD, Ikonomovic MD, DeKosky ST. Human cholinergic basal forebrain: chemoanatomy and neurologic dysfunction. J Chem Neuroanat. 2003;26:233-42

38. Woolf NJ, Gould E, Butcher LL. Nerve growth factor receptor is associated with cholinergic neurons of the basal forebrain but not the pontomesencephalon. Neuroscience. 1989;30:143-52.

39. Pioro EP, Cuello AC. Distribution of nerve growth factor receptor-like immunoreactivity in the adult rat central nervous system. Effect of colchicine and correlation with the cholinergic system---I. forebrain. Neuroscience. 1990:34:57-87.

40. Allaway KC, Machold R. Developmental specification of forebrain cholinergic neurons. Dev Biol. 2017:421:1-7.

41. Elshatory Y, Gan L. The LIM-homeobox gene Islet-1 is required for the development of restricted forebrain cholinergic neurons. J Neurosci. 2008; 28:3291-7.

42. Cho HH, Cargnin F, Kim Y, Lee B, Kwon RJ, Nam H, Shen R, Barnes AP, Lee JW, Lee S, Lee SK. IsI1 directly controls a cholinergic neuronal identity in the developing forebrain and spinal cord by forming cell type-specific complexes. PLoS Genet. 2014:10:e1004280.

43. Minc E, Courvalin JC, Buendia B. HP1gamma associates with euchromatin and heterochromatin in mammalian nuclei and chromosomes. Cytogenet Cell Genet. 2000;90:279-84

44. Capsoni S, Tiveron C, Vignone D, Amato G, Cattaneo A. Dissecting the involvement of tropomyosin-related kinase a and p75 neurotrophin receptor signaling in NGF deficit-induced neurodegeneration. Proc Natl Acad Sci U S A. 2010;107:12299-304.

45. Capsoni S, Amato G, Vignone D, Criscuolo C, Nykjaer A, Cattaneo A. Dissecting the role of sortilin receptor signaling in neurodegeneration induced by NGF deprivation. Biochem Biophys Res Commun. 2013:431:579-85.

46. Moreau K, Fleming A, Imarisio S, Lopez Ramirez A, Mercer JL, JimenezSanchez M, Bento CF, Puri C, Zavodszky E, Siddiqi F, et al. PICALM modulates autophagy activity and tau accumulation. Nat Commun. 2014;5:4998

47. Braak H, Del Tredici K. The pathological process underlying Alzheimer's disease in individuals under thirty. Acta Neuropathol. 2011;121:171-81.

48. Trzeciakiewicz H, Tseng JH, Wander CM, Madden V, Tripathy A, Yuan CX, Cohen TJ. A dual pathogenic mechanism links tau acetylation to sporadic Tauopathy. Sci Rep. 2017:7:44102.

49. Ohia-Nwoko O, Montazari S, Lau YS, Eriksen JL. Long-term treadmill exercise attenuates tau pathology in P301S tau transgenic mice. Mol Neurodegener. 2014;9:54

50. Choi SH, Kim YH, Hebisch M, Sliwinski C, Lee S, D'Avanzo C, Chen H, Hool B, Asselin C, Muffat J, et al. A three-dimensional human neural cell culture model of Alzheimer's disease. Nature. 2014;515:274-8.

51. Eftekharzadeh B, Daigle JG, Kapinos LE, Coyne A, Schiantarelli J, Carlomagno Y, Cook C, Miller SJ, Dujardin S, Amaral AS, et al. Tau protein disrupts Nucleocytoplasmic transport in Alzheimer's disease. Neuron. 2018;99:925-40 e927.

52. Ding $B$, Akter $M$, Zhang CL. Differential influence of sample sex and neuronal maturation on mRNA and protein transport in induced human neurons. Front Mol Neurosci. 2020;13:46

53. Bartus RT, Dean RL 3rd, Beer B, Lippa AS. The cholinergic hypothesis of geriatric memory dysfunction. Science. 1982;217:408-14.

54. Perry EK, Tomlinson BE, Blessed G, Bergmann K, Gibson PH, Perry RH. Correlation of cholinergic abnormalities with senile plaques and mental test scores in senile dementia. Br Med J. 1978:2:1457-9.

55. Smith DK, Yang J, Liu ML, Zhang CL. Small molecules modulate chromatin accessibility to promote NEUROG2-mediated fibroblast-to-neuron reprogramming. Stem Cell Reports. 2016;7:955-69.

56. Wapinski OL, Vierbuchen T, Qu K, Lee QY, Chanda S, Fuentes DR, Giresi PG, $\mathrm{Ng} \mathrm{YH}$, Marro S, Neff NF, et al. Hierarchical mechanisms for direct reprogramming of fibroblasts to neurons. Cell. 2013;155:621-35.

57. Thaler JP, Lee SK, Jurata LW, Gill GN, Pfaff SL. LIM factor Lhx3 contributes to the specification of motor neuron and interneuron identity through celltype-specific protein-protein interactions. Cell. 2002:110:237-49.

58. Galluzzi L, Kepp O, Krautwald S, Kroemer G, Linkermann A. Molecular mechanisms of regulated necrosis. Semin Cell Dev Biol. 2014:35:24-32

59. Fricker M, Tolkovsky AM, Borutaite V, Coleman M, Brown GC. Neuronal cell death. Physiol Rev. 2018:98:813-80

\section{Publisher's Note}

Springer Nature remains neutral with regard to jurisdictional claims in published maps and institutional affiliations. 